\title{
O USO DE JOGOS COMO FERRAMENTA DE ENSINO DE MATEMÁTICA FINANCEIRA
}

\section{THE USE OF GAMES HOW FINANCIAL MATHEMATICS TEACHING TOOL}

Odair José Pin, Ana Paula Brandão de Melo, Roger Gomes Soares da Silva, Eugenia Brunilda Opazo Uribe

Universidade Federal de Mato Grosso do Sul - UFMS, Curso de Licenciatura em Matemática, Três Lagoas, MS. Agência de fomento: Programa de Educação Tutorial E-mail: odairjosepin@gmail.com

RESUMO - O trabalho apresenta resultados de uma atividade de pesquisa desenvolvida no Grupo PET Conexões de Saberes Matemática do Campus de Três Lagoas da Universidade Federal de Mato Grosso do Sul, que visa o estudo de matemática financeira básica aplicada em ações do cotidiano. Como resultado foi desenvolvido o jogo "Corrida Empresarial", que tem como objetivo despertar o interesse dos alunos na área. O jogo envolve ações cotidianas nas quais o jogador calcula juros simples, juros compostos e montantes. 0 desenvolvimento foi realizado através de levantamento bibliográfico, estudo teórico, discussões, apresentação de seminários, preparação e desenvolvimento de uma oficina e elaboração do relatório final. Podemos concluir que o jogo Corrida Empresarial se mostra uma ferramenta útil para o ensino de Matemática Financeira, permitindo uma abordagem lúdica de juros simples e compostos.

Palavras-chave: Matemática Financeira; Jogos; Corrida Empresarial; Juros; Montante.

ABSTRACT - The paper presents results of a research activity developed by the PET Group Knowledge Connections - Mathematics of the Três Lagoas Campus of teh Federal University of Mato Grosso do Sul, aimed at basic financial math study applied in everyday actions. As a result we developed the game "Corporate Race", which aims to arouse the interest of students in the area. The game involves everyday actions in which the player calculates simple interest, compound interest and amount. The development was done through literature, theoretical study, discussions, seminar presentations, preparation and development of a workshop and final report. We can conclude that the Business Race game proves a useful tool for

Recebido em: 19/08/2015 Revisado em: 27/08/2015 Aprovado em: 01/09/2015
Financial Mathematics teaching, allowing a playful approach of simple and compound interest.

Keywords: Financial Mathematics; Games; Corporate Race; Interest; Amount. 


\section{INTRODUÇÃO}

O ensino de matemática financeira é de grande importância para o aluno tanto do ensino fundamental quanto do ensino médio, pois será necessário para toda a vida: desde o ato de comprar um celular até mesmo calcular o desconto em uma loja, escolher pagar a vista ou parcelado, etc., sendo assim tal disciplina deve ser ensinada de maneira única, fazendo com que o aluno tenha total compreensão e domínio dos conceitos básicos.

Almeida (2004), na pesquisa Trabalhando matemática financeira em uma sala de aula do ensino médio da escola pública, propôs para essa turma um trabalho, intitulado "Projeto Cálculo". Por meio de mídias e trocas de experiências entre os alunos, foi possível compreender como eles aprendem a matemática financeira. Segundo ela:

[...] a abordagem de conteúdos de matemática financeira no ensino médio pode contribuir com a formação matemática deste nível de aluno, em como capacitá-lo para entender o mundo em que vive, tornando-o mais crítico ao assistir um noticiário, ao ingressar no mundo do trabalho, ao consumir, ao cobrar seus direitos e analisar seus deveres. (p. 5).

Este trabalho visou construir um modelo de ensino de maneira lúdica e sucinta de alguns tópicos da matemática financeira como, por exemplo, juros simples e juros compostos utilizando como ferramenta de ensino jogos que agucem a curiosidade e que motivem a busca por mais conhecimento. O jogo é sempre uma boa alternativa para o professor que deseje sair do modelo clássico de ensino, pois permite que o aluno interaja mais em sala de aula e deixe de ser apenas um sujeito passivo. Tal mudança de modelo pode ser positiva tanto ao aluno como também ao professor.

\section{METODOLOGIA}

O desenvolvimento do trabalho foi realizado através de uma pesquisa bibliográfica, estudo teórico dos conceitos básicos de Matemática Financeira, discussões em grupo, apresentação de seminários e resolução de exercícios, construção do jogo em papel cartão e E.V.A., preparação e desenvolvimento de uma oficina, analise dos resultados e da avaliação da oficina para implementação de mudanças e adaptações, elaboração do relatório final.

\section{RESULTADOS}

Juros Simples, Juros Compostos $e$ progressões. Para começar a pesquisa, foi preciso rever alguns conceitos utilizados na matemática financeira, com foco nos juros simples, compostos e suas relações com as progressões. O regime de juros será dito simples quando o percentual de juros 
incidirem apenas no valor principal, ou seja, sobre os valores gerados a cada período não incidirá novos valores.

A notação utilizada será a seguinte:

$j:$ Juros

$P$ : Principal

$i$ : Taxa de juros

$n$ : Número de períodos.

M: Montante

Temos que a fórmula do montante de um juro simples, acumulado em certo período de tempo será

$$
M=P+j,
$$

onde $j$ é o capital $P$ multiplicado pela razão $i$ fixa e a variação de tempo $n$. Nesse caso, podemos estabelecer uma conexão com uma progressão aritmética, já que $j$ seria $(m-1) r$. Considerando que a variação de tempo $n$ nada mais é que o número de meses $m$ menos um; e $r$ é a taxa fixa vezes o principal. Mais precisamente, o montante total de uma aplicação com principal de $P$, valor fixo de acréscimo de $i \%$ a.m. em $n$ meses poderia ser calculado por

$$
M=P+(P \cdot i \cdot n)
$$

e a fórmula do termo geral de uma progressão aritmética é

$$
a_{n}=a_{1}+(n-1) \cdot r .
$$

Apesar de ser útil, não vivemos o regime de juros simples. Quando o banco cobra os juros em uma conta corrente, ele usa como método o regime de juros compostos. Estes crescem em progressão geométrica, facilmente analisada pela fórmula do montante. Temos que o montante calculado em juros compostos pode ser obtido pela seguinte fórmula:

$$
M=P \cdot(1+i)^{n},
$$

onde, $M$ será o montante, também chamado de valor futuro (FV ou future value, em inglês). $P$ será o principal, também chamado de Valor Presente ( $P V$ ou present value, em inglês). $i$ é a taxa dos juros e $n$ a variação do tempo. Em uma progressão geométrica, temos:

$$
a_{n}=a_{1} \cdot q^{n-1} .
$$

É verificável que a associação entre progressões e juros, além de facilitar a compreensão, estabelece uma linha direta entre conteúdos e, de certa forma, chama a atenção do aluno. Porém não é o suficiente para despertar maiores interesses.

A proposta inicial da atividade de pesquisa era pesquisar jogos existentes para o ensino de Matemática Financeira. Jogos são ferramentas muito interessantes de ensino, eles servem como um colírio para os olhos desinteressados e despreocupados dos alunos. Os jogos trazem alegria e aprendizagem, bem como despertam o senso 
crítico e ajudam a preparar para a vida fora da sala de aula.

$\mathrm{Na}$ nossa pesquisa bibliográfica encontramos diversos jogos com o objetivo esperado, vamos citar alguns jogos que incentivaram a criação do nosso trabalho:

O jogo do ônibus. Este jogo consiste em uma simulação. Os alunos são passageiros de um ônibus que, a cada parada, cobra uma taxa em porcentagem para acréscimo do valor da passagem. No total, são sete paradas. Calcula-se a cada parada esse acréscimo no valor da passagem, que inicialmente e originalmente custaria $R \$$ 500,00 . Por ser um jogo bem versátil, o valor da taxa e da passagem podem mudar, sem maiores problemas. É um jogo interessante, que estimula o aluno a praticar o cálculo de taxas de juros, porém não existe ganhador, assim desmotivando o aluno a jogar.

\section{Corrida Matemática. O jogo possui}

como base um tabuleiro. Esteticamente, um tabuleiro chama muito mais atenção do que uma folha de papel. Os jogadores percorrem o tabuleiro e, se caírem em uma casa com uma estrela, resolvem um problema de juros simples ou compostos. Se acertarem ganha o direito de jogar novamente. Porém, o principal ponto negativo dele é fazer com que bons alunos em matemática financeira tenham uma grande vantagem, levando o aluno a, praticamente, jogar sozinho.

Banco Imobiliário. É um jogo de tabuleiro e sua temática é sedutora e chama atenção. Mas não é muito aplicável no ensino de juros, por exemplo. Porém, o jogo traz elementos de estratégia e de investimentos que são interessantes e desafiadores.

Baseados na análise destes jogos, ficamos incentivados a criar um jogo completamente novo, que unia a temática de investimentos do Banco Imobiliário, a presença de fatores que mudassem completamente $\mathrm{o}$ jogo da Corrida Matemática, e os constantes cálculos do Jogo do Ônibus.

E assim criamos: "Corrida Empresarial", um jogo que simula donos de uma empresa, que precisam enfrentar os problemas da vida, sem falir. O jogo possui uma estética bem definida, com o intuito de despertar o interesse do aluno. Assim, temos um tabuleiro linear, como uma corrida, peões, dado, uma cartela para registrar o montante atual da empresa e cartas especiais, com ações que podem mudar todo o rumo do jogo.

As regras são bem simples. Inicialmente, é feito um sorteio para decidir o primeiro jogador, e embaralham-se as cartas. Quem tirar o maior número no dado ganha o 
direito de jogar primeiro. Se houver empate entre os maiores números, os jogadores devem realizar o desempate, até que um ganhe. E ele joga de novo para andar com seu peão. Cada jogador começa com um principal de $\mathrm{R} \$ 500,00$. Assim que o jogador tira um número no dado, ele calcula, inicialmente pelo regime de juros simples, o acréscimo em sua conta, com uma taxa de $5 \%$ fixos e uma variação de tempo resultante do número do dado que tirou. Se o aluno tirar 3, por exemplo, ele calcula os juros com uma variação de $5 \%$ a.m. após três meses. Se ele acertar, ele anda o que tirou. Se errar, não andará e nem ganhará nada.

No jogo também há as casas especiais. Se um jogador cair em uma casa especial, ele tira uma carta e lê em voz alta o que ela diz. A maioria delas é de azar, como por exemplo, perder metade do dinheiro ou reduzir a taxa para $2 \%$. Caso a carta retirada for de perda de dinheiro bruto, o jogador anda no dado, mas não calcula os juros. Algumas, porém, serão de sorte, com as quais o jogador terá uma vantagem sobre os outros, como ganhar muito dinheiro ou calcular pelo regime de juros compostos por duas rodadas, que será uma bela vantagem, já que o juro composto cresce em progressão geométrica, e a taxa é maior. Quem ganha dinheiro bruto poderá também calcular os juros.
Caso alguém atingir a chegada, receberá de bônus $\mathrm{R} \$ 500,00$, sem o cálculo de juros. A partir daí é feita a conta e quem tiver o maior montante ganha. Se todos os outros jogadores falirem e sobrar apenas um jogador ele se tornará vencedor, mesmo antes de atingir a chegada.

O interessante do jogo é que as cartas também possuem linguagens da matemática financeira, como o uso de porcentagens, estratégias de investimento, entre outras situações do cotidiano, o que torna a atividade bem mais interessante e divertida.

Para testar as potencialidades e possíveis correções, o jogo foi aplicado aos alunos do Curso de Licenciatura em Matemática da Universidade Federal do Mato Grosso do Sul da cidade de Três Lagoas, em forma de oficina. Primeiramente foi realizado um breve resumo do conteúdo aplicado no jogo, como cálculo de porcentagens, fórmulas de juros simples e compostos e sua relação com progressões. Os resultados da oficina foram muito positivos, pois os alunos interagiram e se sentiram motivados a aprender matemática financeira, além disso, se divertiram bastante, principalmente quando tiravam as cartas especiais, pois elas são misteriosas e mudam todo o rumo do jogo. 


\section{DISCUSSÃO}

Com a oficina, além dos alunos se divertirem, aprenderem e socializarem, eles contribuíram com criação de novas cartas especiais e algumas regras importantes para que o jogo se tornasse mais justo e eficiente. $\mathrm{O}$ jogo em si foi considerado muito bom e atingiu as expectativas esperadas, os alunos tiveram a oportunidade de rever conceitos de progressão aritmética e progressão geométrica, cálculo de porcentagens, cálculo de juros simples e compostos, bem como incorporar termos da Matemática Financeira tais como Montante, Principal, etc.

\section{CONCLUSÃO}

Através desta atividade de pesquisa foi possível a criação de um jogo que será utilizado como ferramenta para o ensino de Matemática Financeira, bem como 0 planejamento de uma oficina para sua experimentação. Como desdobramento deste trabalho de pesquisa, podemos apontar uma atividade de ensino que será o planejamento de uma oficina visando o uso do jogo nas aulas de Matemática Financeira com alunos do Ensino Básico e posteriormente uma atividade de extensão de visita às escolas para a utilização do jogo com alunos e professores do ensino básico.

\section{REFERÊNCIAS}

ALMEIDA, A. C. Trabalhando matemática financeira em uma sala de aula do ensino médio da escola pública. 2004. Disponível em:

<http://www.bibliotecadigital.unicamp.br/do cument/?code=vtls000321201\&fd=y>.

Acesso em: 08/05/2015 